\title{
EFFECTS OF DIFFERENT TYPES OF MULCHING FILMS ON SOIL EVAPORATION AND TEMPERATURE
}

\author{
SUN, S. J. ${ }^{1}-$ ZHU, Z. C. ${ }^{1}-$ CHEN, Z. J. ${ }^{1}-$ WANG, W. ${ }^{1,2}-$ YIN, G. H. ${ }^{2}-$ DONG, K. B. ${ }^{1 *}$ \\ ${ }^{1}$ College of Water Conservancy, Shenyang Agricultural University, Shenyang 110866, China \\ ${ }^{2}$ Institute of Applied Ecology, Chinese Academy of Sciences, Shenyang 110016, China \\ *Corresponding author \\ e-mail:dongkebao@126.com
}

(Received 22 ${ }^{\text {nd }}$ Apr 2019; accepted $12^{\text {th }}$ Jul 2019)

\begin{abstract}
Biodegradable plastic films, which are alternatives to traditional polyethylene plastic films and have similar functions, are incorporated into the soil after the crop season, and could, therefore, increase grain yield and decrease film-residues. In this study, we investigated the effect of three types of biodegradable films mulched (liquid film (LF), multi-functional paper film (MPF), and powder film $(\mathrm{PF})$ ), conventional plastic film mulched (PE) and unmulched (CK) on soil water and temperature in pots without crops. The results showed that cumulative temperature increased markedly under LF, PF, PE, and MPF by $20.3,19.3,24.4$, and $22.7{ }^{\circ} \mathrm{C}$, respectively, compared to CK. The greatest reduction in total evaporation compared to CK was observed under PE $(43.9 \mathrm{~mm})$. Soil evaporation was reduced the most under PE $(36.5 \mathrm{~mm})$; however, the MPF and PF treatments significantly decreased total soil evaporation by $2.7 \mathrm{~mm}$ and $3.1 \mathrm{~mm}$, respectively, compared to CK. Our results indicated that biodegradable films improved the average soil temperature at a depth of $10 \mathrm{~cm}$ and reduced soil evaporation, under MPF and $\mathrm{PF}$ resulting in the greatest overall improvement. We concluded that multi-functional paper film and powder film can be alternatives to traditional polyethylene plastic film.
\end{abstract}

Keywords: water saving in agriculture, biodegradable films, crop yields, green agriculture, environmental pollution

\section{Introduction}

In recent decades, plastic film mulching has been one of the most important agronomic practices impacting crop yields worldwide (Zhang et al., 2016). Many earlier studies have shown that plastic film mulching offers considerable advantages, such as increasing soil temperature, reducing evaporation, improving crop quality and yield, controlling salinity accumulation, and reducing the leaching of fertilizer (Wang et al., 2016; Xu et al., 2006). For these reasons, the utilization of plastic film has increased substantially; similarly, the area mulched has also increased. Previous studies have shown that the worldwide consumption of plastic film has reached 0.5-1.5 million tons per year (Yang et al., 2015). Consumption of plastic film in China accounts for $60 \%$ of the world plastic film demand, making China the largest market in the world for these products (Yang et al., 2015). However, from the environment's perspective, plastic film mulching can cause several environmental issues because of its non-degradable nature. After crop harvesting, the plastic film progressively breaks down into pieces that remain and accumulate in the field (Briassoulis et al., 2013, 2015). Moreover, these residual films have been shown to decrease soil permeability, hinder crop root development, reduce nutrient and moisture absorption by crops, and inevitably result in crop production losses (Yan et al., 2006). Many measures have been undertaken to counter these problems, including burning and recycling of plastic films or disposal in landfills (Kyrikou and Briassoulis, 2007). In China, however, the recovery rate of plastic films from the fields was very low because of high labor costs and 
poor efficiency of the recovery machinery (Zhang et al., 2016). Thus, an increasing number of studies have been conducted to develop eco-friendly alternative mulch products that satisfy all the desired functional properties of plastic films (Touchaleaume et al., 2016). Alternative mulching products such as biodegradable films, which have properties similar to conventional plastics but are decomposed and catabolized by microorganisms into carbon dioxide and water over time, are being increasingly used for crop production as they represent a sustainable agronomic solution (Costa et al., 2014). Studies have indicated that biodegradable film can theoretically reduce disposal and labor costs markedly by becoming incorporated directly into the soil rather than requiring disposal by burning or landfill use (Kasirajan and Ngouajio, 2013). Additionally, the biodegradable film had considerable beneficial effects on soil temperature and water content by reducing heat loss and evaporation (Ren et al., 2016). However, different biodegradable films have different functional properties. Studies have shown that some biodegradable films do not have a significant influence on soil water content and temperature because of their short lifespan. Moreover, it has also been suggested that the degradation rate of some biodegradable films is low, causing more serious problems than residual films. Taken together, these results suggest that the development of new types of biodegradable films is required to consistently improve their performance in the field.

In this study, three new types of biodegradable films and their effect on soil water content and temperature were investigated. The first film was a liquid mulching film; this is a new kind of agricultural product that is mainly manufactured from organic polymer materials. It is sprayed or poured onto the soil surface and dries to form a durable, permeable film that connects with soil particles to form a special soil membrane structure; this allows the plant to breathe and water to penetrate, thereby aiding moisture retention and prevention of scattering of solid fertilizers (Yin et al., 2013). The second film was a powder mulching film (humic acid-degradable film) that is mainly manufactured from the raw material humic acid. It can also be sprayed onto the fields to form a durable and biodegradable black film that helps retain moisture and improve soil conditions (Tian et al., 2008). The third film was a multi-functional paper film that not only has good mechanical strength, light transmission, water penetration, and water and heat preservation properties, but also can degrade naturally over a certain period of time (Zhou and Zhu, 2002); this film is produced from plant paper pulp and annexing agents such as wet strength and transparent agents.

In this study, these three different types of degradable mulching films were used as soil mulch to compare their effects with common plastic films and a non-mulching control. The effects and characteristics of the different mulch films on soil moisture and temperature were determined. The results of this study will be useful for farmers in selecting more suitable field mulch films, and for smallholders in improving their products and increasing the yield in future.

\section{Materials and methods}

The experiments were conducted from 7 September to 15 November 2014 in the rainprotection shed of the Liaoning Province Key Laboratory of Water Saving (Institute of Applied Ecology, Chinese Academy of Sciences) that is located in Shenyang city, Liaoning Province. It is situated at $41^{\circ} 10^{\prime} \mathrm{N}-42^{\circ} 12^{\prime} \mathrm{N}$ latitude and $123^{\circ} 20^{\prime} \mathrm{E}-123^{\circ} 45^{\prime} \mathrm{E}$ longitude at a height of $44.7 \mathrm{~m}$ above sea level. This area is characterized by temperate semi-humid continental climate, with a daily average of $6 \mathrm{~h}$ of sunshine. 
The soil was collected from Fuxin Mongolian autonomous county of Liaoning province. The type of soil is brown earth and the texture is sandy loam. Prior to the experiment, the soil was dried and ground through a 5-mm sieve.

We used the following films: polyethylene plastic film (width of $200 \mathrm{~mm}$, thickness of $0.01 \mathrm{~mm}$ ); powder film (fully degradable plastic powder); liquid membrane (fully degradable liquid mulch film); and multi-functional paper film.

In this experiment, five treatments were used: mulching with (a) polyethylene plastic film (PE), (b) liquid film (LF), (c) multi-functional paper film (MPF), or (d) powder film (PF), and (e) an unmulched control (CK) (Fig. 1). The experiment was conducted in a randomized complete design and each treatment repeated three times. Each pot was filled with $10 \mathrm{~kg}$ of soil to which $3.6 \mathrm{~kg}$ of water was added to achieve an average soil moisture content of $28 \%$. The pot height is $30 \mathrm{~cm}$ and the upper and lower inner diameters are $26 \mathrm{~cm}$ and $18 \mathrm{~cm}$, respectively and the height of soil in pot is $25 \mathrm{~cm}$.

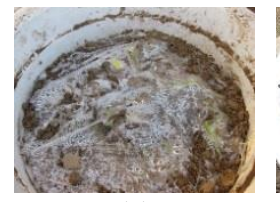

(a)

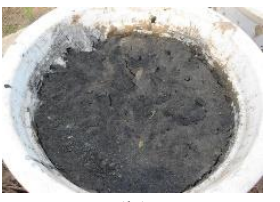

(b)

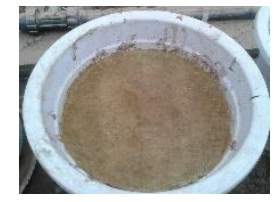

(c)

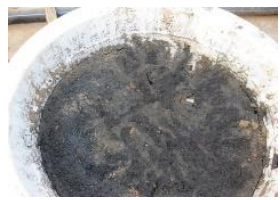

(d)

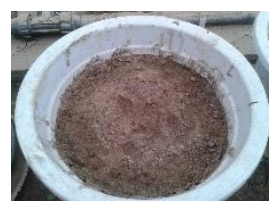

(e)

Figure 1. The different treatments used in this experiment

The weight of each pot was measured at 9:00 A.M. on the first day using an electronic balance with an accuracy of $0.005 \mathrm{~g}$. The pots were weighed daily for the first $20 \mathrm{~d}$ after the films were mulched, every $2 \mathrm{~d}$ from 20 to $40 \mathrm{~d}$, and every $5 \mathrm{~d}$ from $40 \mathrm{~d}$ to $70 \mathrm{~d}$. The amount of evaporation between two time-points was calculated as the difference between the weight of the pots at those two time-points. For each treatment, the cumulative soil evaporation was the difference between the weight of the first pot and the weight of the last pot and then it was converted to expressed in millimeters.

Soil temperature was measured at depths of 5 and $10 \mathrm{~cm}$ using a geothermometer at 9:00 A.M every $3 \mathrm{~d}$ from the first day to the last day of the experiment. For each treatment, the cumulative soil temperature was the sum of all recorded temperatures.

The liquid membrane was observed using a Quanta 250 environmental scanning electron microscope at half a month and four months respectively after it was mulched

SPSS software (version 20) was used for statistical analysis of the experimental results. The effects of the treatments on the measured parameters (soil evaporation and soil temperature) were evaluated using one-way analysis of variance (ANOVA). Least significant differences (LSD) were used to analyze the differences between the means of treatments. The differences were considered statistically significant with a threshold of $\mathrm{p} \leq 0.05$.

\section{Results and discussion}

\section{Effect of different treatments on soil moisture}

Differing patterns of soil evaporation (soil water change) were observed under different mulch treatments from 7 September to 15 November 2014. This is consistent with the different materials having different effects on evaporation (Fig. 2). Figure 2 shows that 
mean soil evaporation of MPF, PF, LF and CK during the experiment period were 1.1, 1.1, 1.2 and $1.2 \mathrm{~mm}$, respectively, which are significantly higher than that of PE $(0.2 \mathrm{~mm})$. In addition, soil water evaporation fluctuated more under the biodegradable film treatments (MPF, PF, and LF) and the control (CK), which coefficient of variance were $89 \%$, $83 \%, 87 \%$ and $82 \%$ respectively, than the PE treatment (47\%). These results indicated that the polyethylene plastic film was able to better prevent evaporation than the biodegradable films; this is consistent with previously reported results (Ren et al., 2016). Costa et al. (2014) also reported that the average soil water content under the PE treatment was markedly higher than that under the biodegradable film mulching treatments. Marked variations in soil water evaporation under the biodegradable film mulching treatments and CK were recorded in first twenty days mainly because of the higher air temperature and longer lighting time in September; this seasonal pattern also likely explains that greater fluctuation in evaporation observed in September than after September. Figure 3 shows that although evaporation under PE was lower than that under the three biodegradable film mulching treatments, the MPF and PF treatments greatly improved moisture retention in comparison with CK. This result is consistent with the results of Ren et al. (2016), who found that the use of biodegradable films considerably reduced soil water evaporation and enhanced the retention of soil moisture, and those of Wang et al. (2016), who reported that the use of biodegradable films resulted in soil water storage values between $90.4 \%-95.4 \%$ of those obtained under the PE treatment. Taken together, these results indicate that biodegradable films are acceptable substitutes for plastic film in terms of moisture retention.

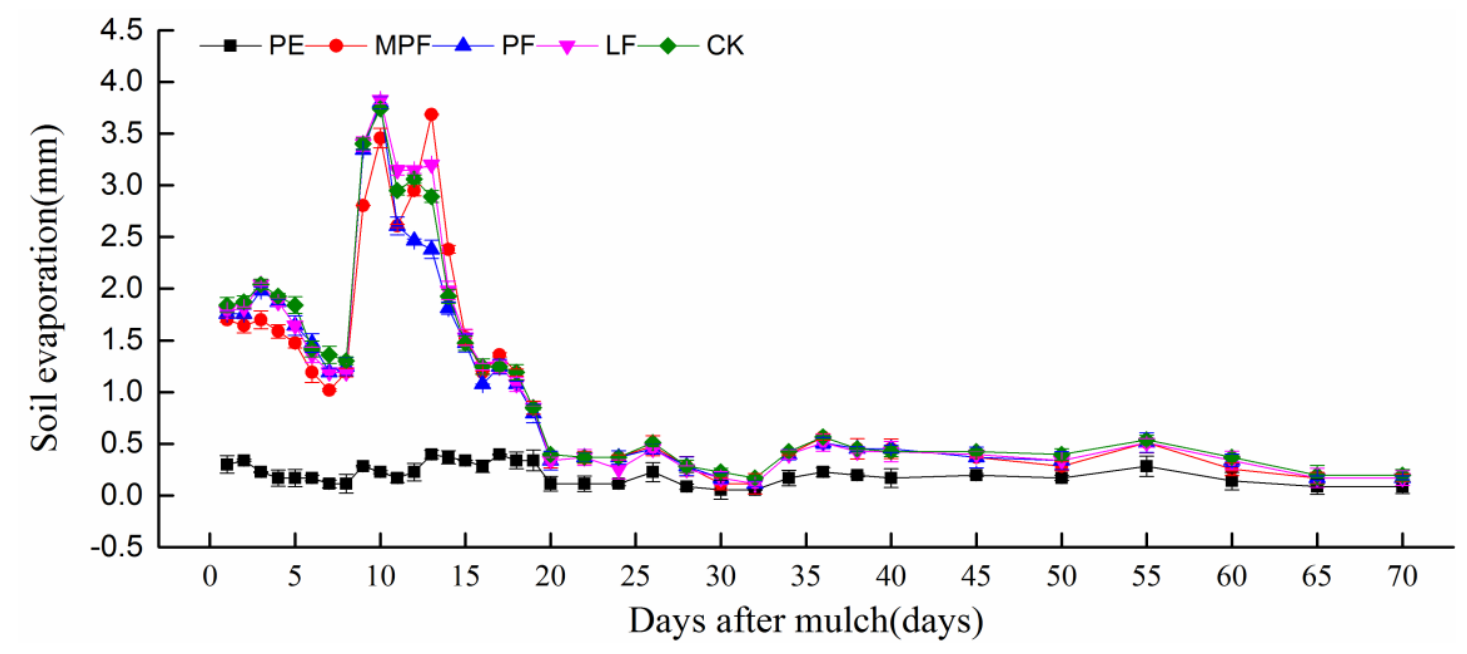

Figure 2. Changes in soil moisture under different treatments

The total evaporation for different mulching treatments are illustrated in Figure 3. Generally, the total amount of soil evaporation under the mulching treatments was significant less than for CK. Compared to CK, the, LF, PF, PE, and MPF treatments reduced the total evaporation by, $0.7,3.1,36.5$ and $2.7 \mathrm{~mm}$, representing $1.6 \%, 7.1 \%$, $83.0 \%$, and $6.0 \%$ of the evaporation observed under CK, respectively. Overall, the total soil moisture evaporation was the lowest under PE and higher under PF, MPF, and LF in that order. This was similar to the results of a four-year field study in semi-arid areas, such as the Loess Plateau, conducted by Ren et al. (2016), who found that the PE treatment showed markedly higher soil moisture than the liquid film mulching and nonmulching treatments. 


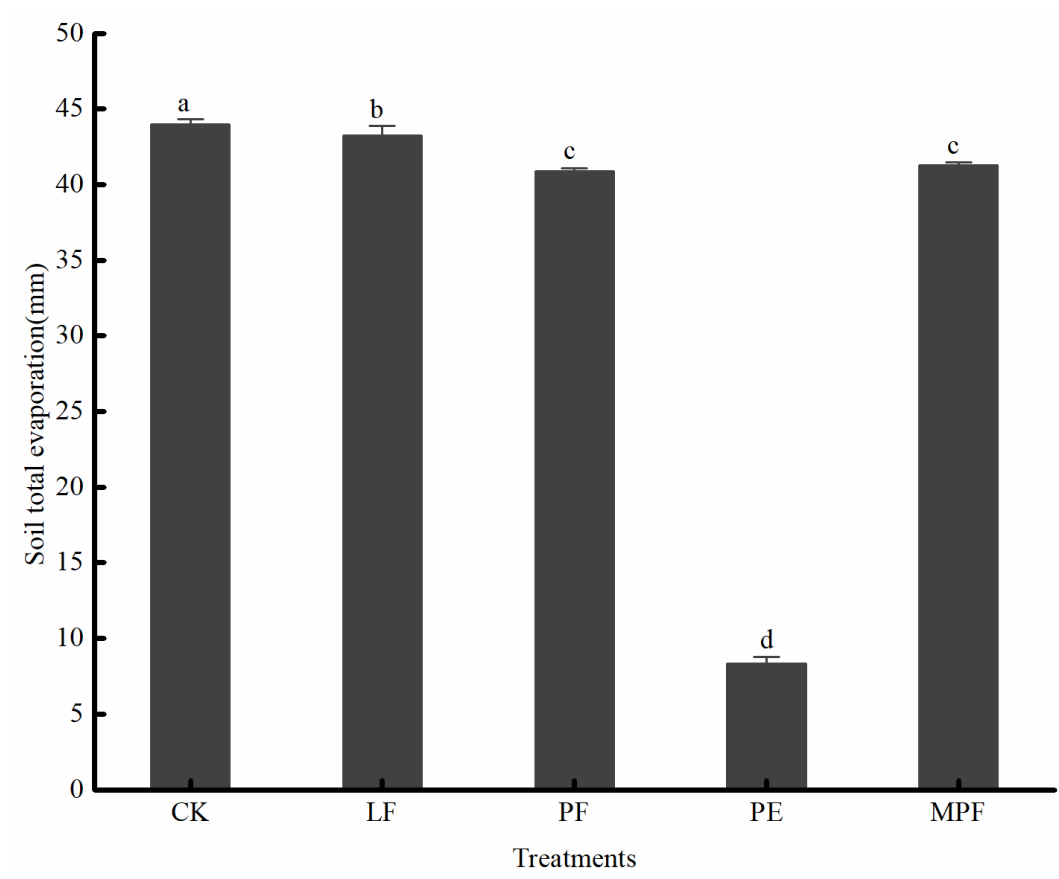

Figure 3. Total evaporation under different treatments. (Different lowercases in a group indicate significant differences at $p=0.05$ level among different treatments)

\section{Effect of different treatments on soil temperature}

The trends in soil temperature were almost identical under the five treatments, likely because of the effects of air temperature. Many previous studies have suggested that topsoil temperature is affected considerably by air temperature (Bai et al., 2015). Consistent with these, we also found that average soil temperature at the depth of $10 \mathrm{~cm}$ was generally significantly affected by mulching ( $\mathrm{p}<0.05)$ (Fig. 4). The experimental results showed that mean soil temperature under the four mulching treatments was significantly higher than under CK. This result is consistent with a previous study that showed mean soil temperature was effectively enhanced by mulching with plastic films and biodegradable films (Ren et al., 2016). Figure 4 also illustrates that at different stages of the experiment, the warming effects of different mulching materials differed. From $25 \mathrm{~d}$ to $50 \mathrm{~d}$ after the start of the experiment, the soil temperature was the highest under PE, indicating that PE has a stronger effect on soil temperature. This result is in agreement with those of previous studies (Costa et al., 2014; Ren et al., 2016). In the first $25 \mathrm{~d}$ of the experiment, however, the soil temperature under LF and MPF was higher that under PE, probably because in the first $25 \mathrm{~d}$ of the experiment, stable structures formed under MPF and LF were more useful in early stage. In the last $20 \mathrm{~d}$ of the experiment, although the soil temperature increased with air temperature about $55 \mathrm{~d}$ after mulching, there were no significant differences in soil temperature between the four mulching treatments. The reason is that in the last mulching period (in November), the air temperature was relative low and had not significant influence on soil.

The cumulative soil temperatures under different treatments are shown in Figure 5. For the mulching treatments, all the cumulative mean soil temperatures were markedly higher than for $\mathrm{CK}$. Compared to $\mathrm{CK}$, the cumulative temperatures under LF, PF, PE, and MPF were increased by $20.3,19.3,24.4$, and $22.6{ }^{\circ} \mathrm{C}$, representing $5.0 \%, 4.8 \%$, 
$6.0 \%$, and $5.6 \%$ of the cumulative temperature of CK. These findings are consistent with the results of other studies (Bai et al., 2015; Li et al., 2012). Liu (2012) reported that there were significant warming effects under biodegradable film treatments compared to $\mathrm{CK}$. Moreover, $\mathrm{Hu}$ (2015) demonstrated that the use of biodegradable film in maize cultivation considerably improved the soil temperature at the depth of $10 \mathrm{~cm}$. Notably, Figure 5 illustrates that the cumulative temperature was the highest under PE, being 4.1, 5.1, and $1.7^{\circ} \mathrm{C}$ higher than that under LF, PF, and MPF, respectively. This is consistent with the results of Bai et al. (2015), who found that the mean temperature at the depth of $25 \mathrm{~cm}$ was increased by $1.0^{\circ} \mathrm{C}$ under PE, compared to biodegradable film. Although the cumulative temperature was lower under LF, PF, and MPF than under PE, these three treatments still had considerably higher cumulative temperatures than CK. A similar result was obtained by Costa et al. (2014) who reported that biodegradable film mulching improved soil warming and provided highly favorable conditions for crop growth. Taken together, these results indicate that biodegradable polymers, because of the warming effects of the biodegradable film, are sustainable alternatives to PE films in some agricultural production systems.

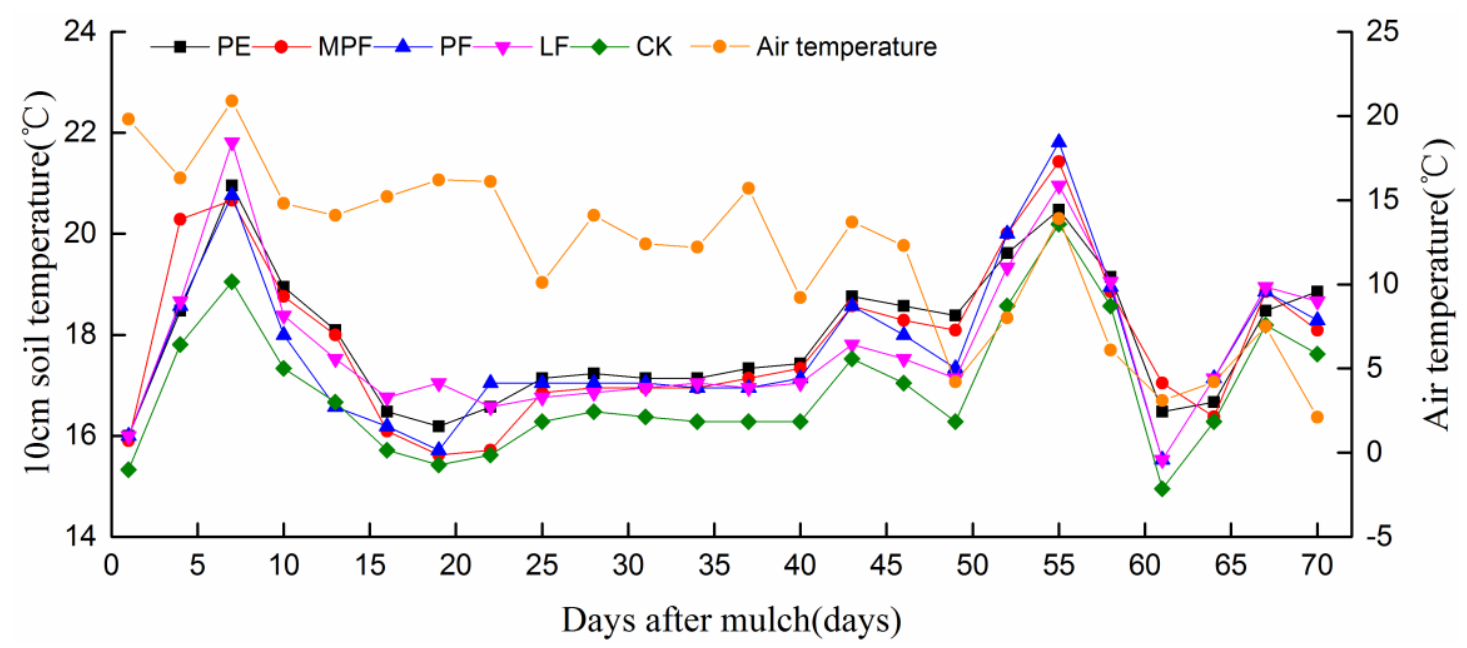

Figure 4. Soil temperature at the depth of $10 \mathrm{~cm}$ under different treatments

\section{Modelling the effects of time spent mulched by film and soil temperature on total soil evaporation}

Soil moisture is an important factor affecting crop growth; film mulching could reduce excessive soil moisture evaporation and improve soil temperature. Therefore, evaluation of the effects of different film mulching treatments on soil evaporation may provide useful information regarding selecting mulching planting technologies. The time spent mulched by a film and the soil temperature were chosen as independent variables that affect changes in soil moisture content, and the total variation in total evaporation under different treatments was chosen as the dependent variable to establish a regression model using SPSS 20.0; this model was used to analyze the effects of filmmulched time and soil temperature on total soil evaporation. The results are shown in Table 1.

Table 1 shows that the least adjusted R-square of all treatments was 0.69 at $\mathrm{p}<0.05$; this indicates that the linear equations effectively and adequately represent the 
relationship between soil evaporation, soil temperature and mulching time. A negative relationship between evaporation and mulching time was obtained from the linear equations of LF, PF, MPF, and PE. This suggests that a long film- mulched time would reduce the total evaporation of soil moisture. In contrast, a higher soil temperature would result in increased evaporation.

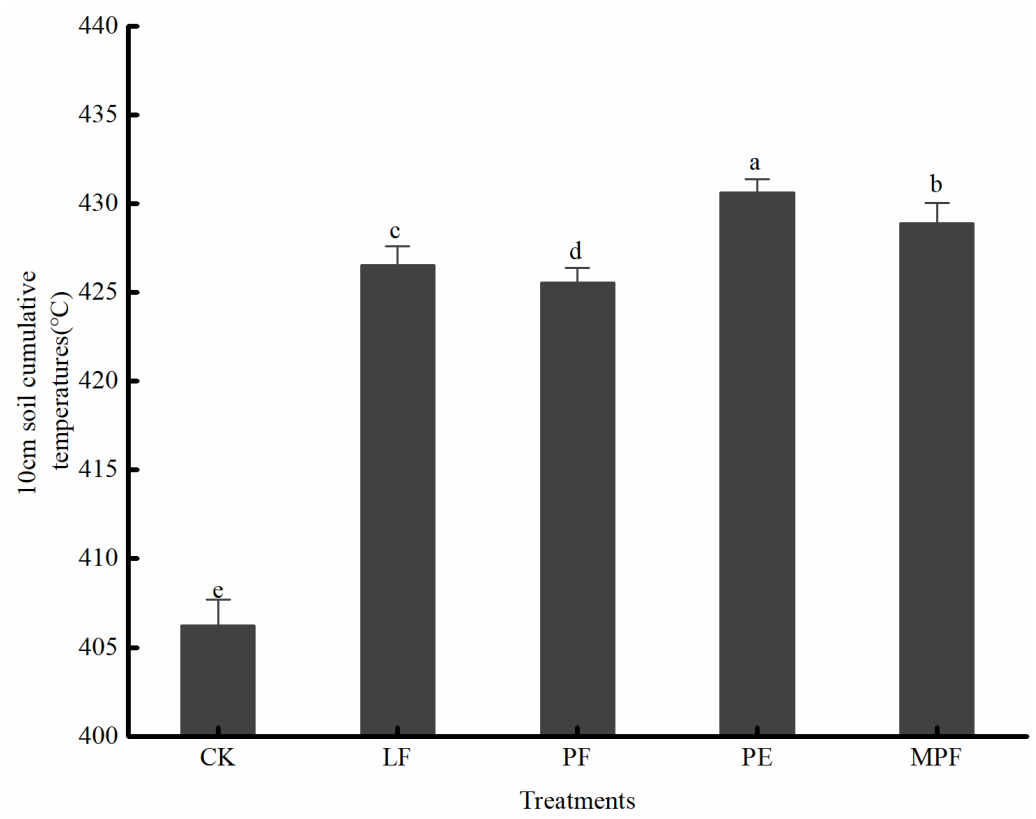

Figure 5. Cumulative soil temperature under different treatments. (Different lowercases in a group indicate significant differences at $p=0.05$ level among different treatments)

Table 1. Soil moisture model under different treatments

\begin{tabular}{c|c|c|c}
\hline Treatment & Linear relationship & $\begin{array}{c}\text { Adjusted R } \\
\text { Square }\end{array}$ & Sig. \\
\hline Liquid film & Evaporation $=0.001-\mathrm{t}^{*} 0.002+0.004 * \mathrm{~T}$ & 0.746 & $.000^{\mathrm{b}}$ \\
Powder film & Evaporation $=0.007-\mathrm{t}^{*} 0.002+0.003 * \mathrm{~T}$ & 0.826 & $.000^{\mathrm{b}}$ \\
Paper film & Evaporation $=0.025-\mathrm{t}^{*} 0.002+0.002 * \mathrm{~T}$ & 0.694 & $.000^{\mathrm{b}}$ \\
Plastic film & Evaporation $=0.008-\mathrm{t}^{*} 0.002+0.04 * \mathrm{~T}$ & 0.718 & $.000^{\mathrm{b}}$ \\
\hline
\end{tabular}

t: time spent mulched; $\mathrm{T}$ : cumulative temperature

\section{Microscopic effects of liquid film on soil structure}

Combination of liquid film and soil particles

Microscopic analysis of the effects of liquid film on soil structure is shown in Figure 6. The results show that many small particles are combined into large particles on the soil surface by sticky flocculated colloid. Between these large particles, there were many fabric couplings that were similar to the chemical bonding that occurs in molecular structures. These couplings could connect two or more of the soil particles, allowing them to form a stable structure. In addition, these fabric couplings have a strong bonding force that makes soil particles connect in a lattice frame rather than "point to point". 
When soil particles were mulched by the liquid film, the physical and chemical properties of soil improved and the accumulation of organic matter contributed to the formation of soil membrane structure that enhanced the stability of the soil surface.
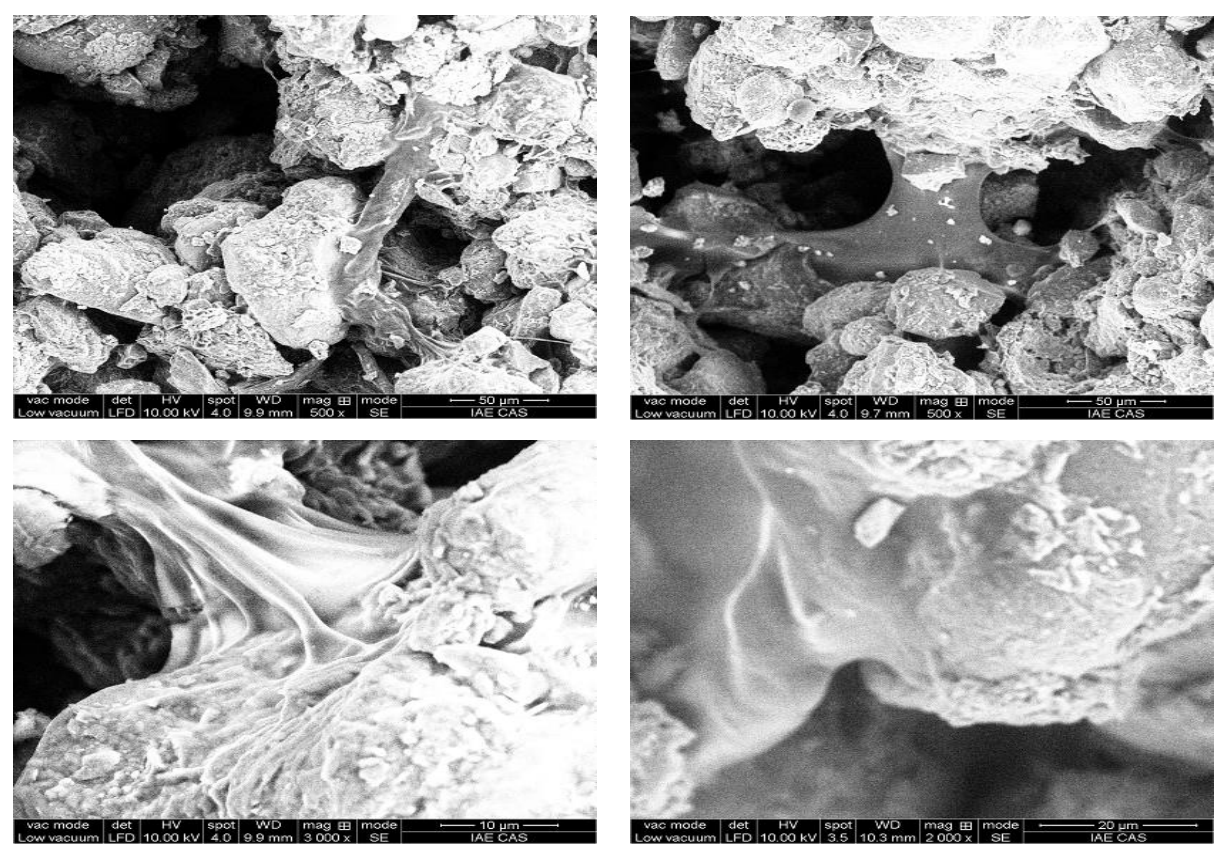

Figure 6. Connection of the liquid film with soil particles

\section{Surface tension of the membrane structure}

Surface tension of the membrane structure is illustrated in Figure 7. These images show that even with the irregular size of soil particles and the irregular size of the pores between particles, the membrane can make a tight connection between rough soil particles through the surface tension of the liquid membrane. Regardless, the surface tension of the liquid membrane on the surface of soil particles was easily broken. As shown in Figure 7, the liquid membrane between the soil particles was prone to damage, thereby reducing the films moisture-retaining effects. This likely explains why evaporation was higher under LF than under the other two biodegradable film mulching treatments (Fig. 3).
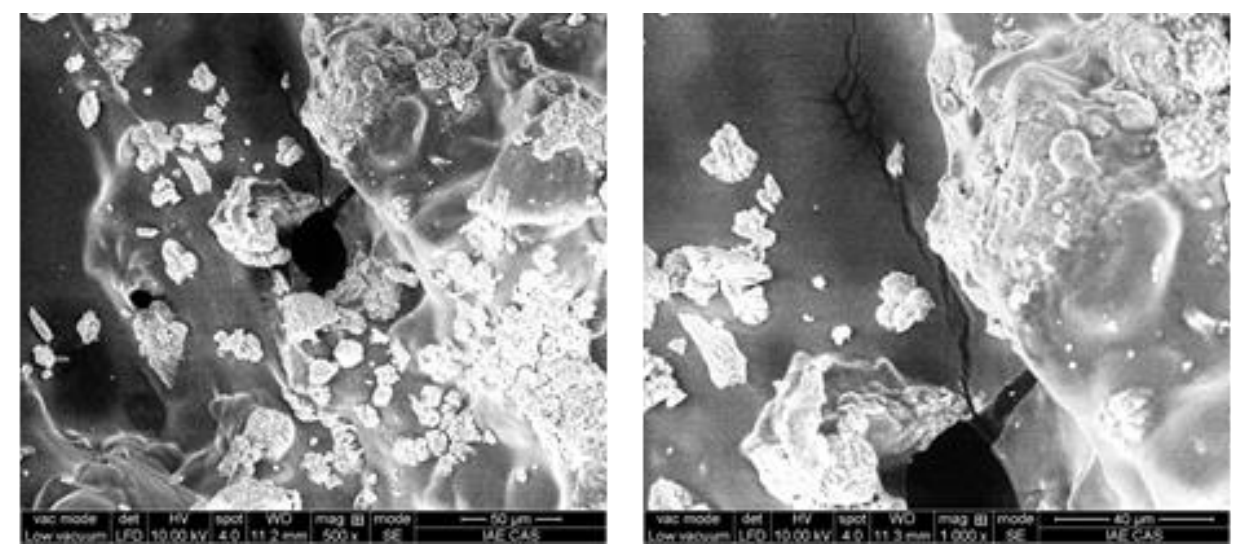

Figure 7. The surface tension of the membrane structure 


\section{Conclusion}

Three biodegradable mulching films (liquid film, powder film, and multi-functional paper film) were used in this study and compared with the common plastic film and an untreated, unmulched control. Significantly less evaporation was observed under powder film, multi-functional paper film, and polyethylene plastic film treatments relative to CK. In terms of water retention, plastic mulch film was the best, followed by powder film and multi-functional paper film, with the liquid mulch having the lowest water retention of the tested films.

Soil warming was enhanced by mulching with plastic and biodegradable films. Moreover, soil temperature was the highest under the plastic film, followed by multifunctional paper film, powder film, and finally liquid film. The increase in cumulative soil temperature was significantly higher in the early stages of the experiment than in the later stages.

Scanning of the soil microstructure using an electron microscope showed that the correct spraying of liquid membrane could effectively cement soil particles together and reduce moisture evaporation. However, the stable structure formed by the liquid film degraded easily, accounting for the reduced moisture-retaining and warming effects that were observed under the liquid film compared to the other biodegradable film treatments.

The results of this study indicate that, currently, the effects of biodegradable films on water retention and conservation of soil temperature are still inferior to plastic films. Biodegradable film producers should, therefore, further improve their products to meet future agricultural development needs.

Acknowledgements. This work was supported by the China Special Fund for Agro-scientific Research in the Public Interest (No. 201303125), the Natural Science Foundation of Liaoning Province, China (No. 20180550617), the Scholarship of China Scholarship Council (No. 201308210026).

\section{REFERENCES}

[1] Bai, Y. S., Jia, S. H., Huang, C. X., Luo, T. F. (2015): Effect of biodegradable film on soil temperature, moisture and yield of spring wheat in dryland. - Journal of Triticeae Crop 35(11): 1558-1563 (in Chinese).

[2] Briassoulis, D., Babou, E., Hiskakis, M., Scarascia, G., Picuno, P., Guarde, D., Dejean, C. (2013): Review, mapping and analysis of the agricultural plastic waste generation and consolidation in Europe. - Waste Management \& Research the Journal of the International Solid Wastes \& Public Cleansing Association Iswa 31(12): 1262-1278.

[3] Briassoulis, D., Babou, E., Hiskakis, M., Kyrikou, L. (2015): Analysis of long-term degradation behaviour of polyethylene mulching films with pro-oxidants under real cultivation and soil burial conditions. - Environmental Science and Pollution Research 22(4): 2584-2598.

[4] Costa, R., Saraiva, A., Carvalho, L., Duarte, E. (2014): The use of biodegradable mulch films on strawberry crop in Portugal. - Scientia Horticulturae 173: 65-70.

[5] Hu, H. L. (2015): Studies on Yield Effects, Degradation Properties of Biodegradable Mulch Film and Its Field Demonstration. - Zhejiang University, Zhejiang (in Chinese).

[6] Kasirajan, S., Ngouajio, M. (2013): Erratum to: Polyethylene and biodegradable mulches for agricultural applications: a review. - Agronomy for Sustainable Development 33(2): 443-443. 
[7] Kyrikou, I., Briassoulis, D. (2007): Biodegradation of agricultural plastic films: a critical review. - Journal of Polymers and the Environment 15(2): 125-150.

[8] Li, R., Wang, M., Jia, Z. K., Hou, X. Q., Yang, B. P., Han, Q. F., Nie, J. F., Zhang, R. (2012): Effects of different mulching patterns on soil temperature, moisture water and yield of spring maize in Weibei Highland. - Transactions of the Chinese Society of Agricultural Engineering 28(2): 106-113 (in Chinese).

[9] Liu, Q. (2012): Degradation of Biodegradable Mulch Film and Its Effect on Growth and Yield of Maize. - Northwest A\&F University, Shanxi (in Chinese).

[10] Ren, X. L., Zhang, P., Chen, X. L., Guo, J. J., Jia, Z. K. (2016): Effect of Different Mulches under Rainfall Concentration System on Corn Production in the Semi-Arid Areas of the Loess Plateau. - Scientific Reports 6: 19019.

[11] Tian, Y. Y., Qiao, Y. Y., Guo, S. Y. (2008): Humic acid multifunctional degradable film (powder) standard draft. - Humic Acid 3: 47-50.

[12] Touchaleaume, F., Martin-Closas, L., Angellier-Coussy, H., Chevillard, A., Cesar, G., Gontard, N., Gastaldi, E. (2016): Performance and environmental impact of biodegradable polymers as agricultural mulching films. - Chemosphere 144: 433-439.

[13] Wang, S. Y., Fan, T. L., Li, S. Z., Zhang, J. J., Zhao, G., Wang, L., Dang, Y., Jiang, X. F. (2016): Property of biodegradable film degradation, water-retention and increasing soil temperature and its impact on maize growth and development process. - Agricultural Research in the Arid Areas 34(1): 127-133 (in Chinese).

[14] Xu, X. C., Wang, C. Y. (2006): The status and development trend of cultivation mulch film at home and abroad. - Plant Fibers and Products 28(1): 6-11.

[15] Yan, C. G., Mei, X. R., He, W. Q., Zheng, S. H. (2006): Present situation of residue pollution of mulching plastic film and controlling measures. - Transactions of the Chinese Society of Agricultural Engineering 22(11): 269-272 (in Chinese).

[16] Yang, N., Sun, Z. X., Feng, L. S., Zheng, M. Z., Chi, D. C., Meng, W. Z., Hou. Z. Y., Bai, W., Li, K. Y. (2015): Plastic film mulching for water-efficient agricultural applications and degradable films materials development research. - Advanced Manufacturing Processes 30(2): 143-154.

[17] Yin, G. H., Hao, L., Zhao, Y. H., Gu, J., Liu, Z. X. (2013): Effects of hydromulching on soil water availability. - Chinese Journal of Ecology 32(6): 1405-1411 (in Chinese).

[18] Zhang, D., Liu, H. B., Hu, W. L., Qin, X. H., Ma, X. W., Yan, C. R., Wang, H. Y. (2016): The status and distribution characteristics of residual mulching film in Xinjiang, China. Journal of Integrative Agriculture 15(11): 2639-2646.

[19] Zhou, J. H., Zhu, H. G. (2002): Research and application of paper film. - China Pulp and Paper 5: 56-58 (in Chinese). 